\title{
Jefferson
}

Thomas Jefferson University

$\overline{\text { HOME OF SIDNEY KIMMEL MEDICAL COLLEGE }}$

JHN Journal

Volume 14

Issue 1 Summer 2019

Article 3

Summer 2019

\section{Multiple Contiguous-Level Cervical Disc Arthroplasties: Unique Considerations}

Alejandro J. Lopez, DO

Philadelphia College of Osteopathic Medicine

Jonas Gopez, MD

Abington Jefferson Health

Follow this and additional works at: https://jdc.jefferson.edu/jhnj

\section{Let us know how access to this document benefits you}

\section{Recommended Citation}

Lopez, DO, Alejandro J. and Gopez, MD, Jonas (2019) "Multiple Contiguous-Level Cervical Disc Arthroplasties: Unique Considerations," JHN Journal: Vol. 14 : Iss. 1 , Article 3.

DOI: https://doi.org/10.29046/JHNJ.014.1.003

Available at: https://jdc.jefferson.edu/jhnj/vol14/iss1/3

This Article is brought to you for free and open access by the Jefferson Digital Commons. The Jefferson Digital Commons is a service of Thomas Jefferson University's Center for Teaching and Learning (CTL). The Commons is a showcase for Jefferson books and journals, peer-reviewed scholarly publications, unique historical collections from the University archives, and teaching tools. The Jefferson Digital Commons allows researchers and interested readers anywhere in the world to learn about and keep up to date with Jefferson scholarship. This article has been accepted for inclusion in JHN Journal by an authorized administrator of the Jefferson Digital Commons. For more information, please contact: JeffersonDigitalCommons@jefferson.edu. 


\section{Multiple Contiguous-Level Cervical Disc Arthroplasties: Unique Considerations}

\author{
Alejandro J. Lopez, DO1; Jonas Gopez, MD ${ }^{1,2}$ \\ ${ }^{1}$ Department of Neurological Surgery, Philadelphia College of Osteopathic Medicine, \\ Philadelphia, PA, 19131 \\ 2 Department of Neurological Surgery, Abington Hospital - Jefferson Health, Abington, PA 19001
}

\begin{abstract}
Arthroplasty is an established treatment for single and multiple level cervical disc disease. Multiple contiguous arthroplasties introduce unique changes in spinal kinematics that warrant study independent of single-level surgery. The literature regarding the biomechanics, indications, outcomes and complications specific to multiple level arthroplasties was reviewed. Appropriate application of this technology has been shown to be a safe and potentially advantageous alternative to arthrodesis.
\end{abstract}

\section{INTRODUCTION}

Cervical disc arthroplasty (CDA) is an alternative to anterior cervical discectomy and fusion (ACDF) for the treatment of cervical disc disease. Developed with the intention of preserving or restoring motion of a degenerated disc, CDA has been proposed to reduce rates of adjacent segment degeneration and disease. ${ }^{1-4}$

A single-level ACDF reduces the cervical range of motion approximately 7 degrees, while CDA preserves or may even increase motion at that segment. ${ }^{5-10}$ The benefit of replicating physiologic motion to prevent adjacent segment disease has been the subject of debate, with several current meta-analyses advocating the use of CDA over ACDF for single level disease for this reason. ${ }^{11-13}$ Evidence includes a randomized control trial reporting a significant decrease in the rate of subsequent surgery at 7 years follow up for single level CDA compared to ACDF. ${ }^{14}$

The generalizability of these data to multilevel disease is unclear. Inclusion criteria for many randomized controlled trials excluded multilevel treatments or, if multilevel CDA was included, those data were often not analyzed independently of single-level results. The purpose of this review is to examine the unique considerations and literature of multilevel CDA.

\section{BIOMECHANICS}

Adjacent segment disease (ASD), defined by Hilibrand as new and symptomatic degenerative changes after fusion, ${ }^{15}$ has been attributed to compensatory biomechanical stresses at levels above and below a fusion, ${ }^{16}$ which approximately $25 \%$ of patients who undergo ACDF will experience within 10 years from surgery. ${ }^{17}$ Most biomechanical studies on multilevel CDA were designed to investigate this phenomenon.

The degree of additional stress at adjacent levels is commonly quantified by measurements of intradiscal pressure and mobility. ${ }^{16,18}$ In multilevel ACDF, adjacent discal pressures have been shown to increase by 3-6.7 fold, while CDA either maintains or even decreases adjacent level pressures. ${ }^{19-22}$

In a cadaveric load-control study, Phillips found that a single CDA at C5/6 increased flexion-extension of that motion segment by 4 degrees but did not significantly change rotation or lateral bending. The adjacent segments' motions were unchanged. Upon implanting a second CDA at C6/7, lateral bending of the superior adjacent level (C4/5) increased. A single CDA at C6/7 did not reproduce the increase in flexion-extension or adjacent level mobility. This suggests that multilevel arthroplasty introduces unique spinal kinematics and that the effects may be level-dependent. In vivo, multilevel arthroplasty has demonstrated no significant difference from pre-operative motion at the operated levels. ${ }^{23,} 24$

Authors have proposed that biomechanical stresses are additive with consecutive levels of arthrodesis due to increased constraint and suggest that arthroplasty may help defray the mechanical disadvantages of a multilevel fusion; ${ }^{16}$ however, a recent meta-analysis reported that the highest prevalence of ASD was in single level $A C D F$, significantly more than in multilevel fusion. ${ }^{25}$ This contradicts finite element analyses wherein longer segment anterior fusions have been shown to increase adjacent level intradiscal stresses. ${ }^{26}$ While the authors of the meta-analysis suggest that multilevel procedures might have already addressed the most at-risk levels, the etiologies of ASD and how the biomechanics of arthroplasty affect them have not been fully reconciled with clinical data.

\section{INDICATIONS/PATIENT SELECTION}

Multiple devices have FDA approval for single and multilevel cervical disc arthroplasty. Randomized controlled trials on multilevel arthroplasty selected for patients with degenerative disc disease causing radiculopathy or myelopathy and excluded patients with pathology outside of C3-7.23, 24, 27 Expanded indications have been reported, including acute traumatic disc herniations ${ }^{28}$ and use in upper thoracic levels. ${ }^{29}$

Contraindications include less than three millimeters of available disc space to avoid excessive loading of the posterior elements by overdistracting anteriorly. ${ }^{30}$ Kyphotic deformity of greater than 15 degrees may indicate concomitant posterior element pathology that could be exacerbated by increasing motion at that segment. Other 

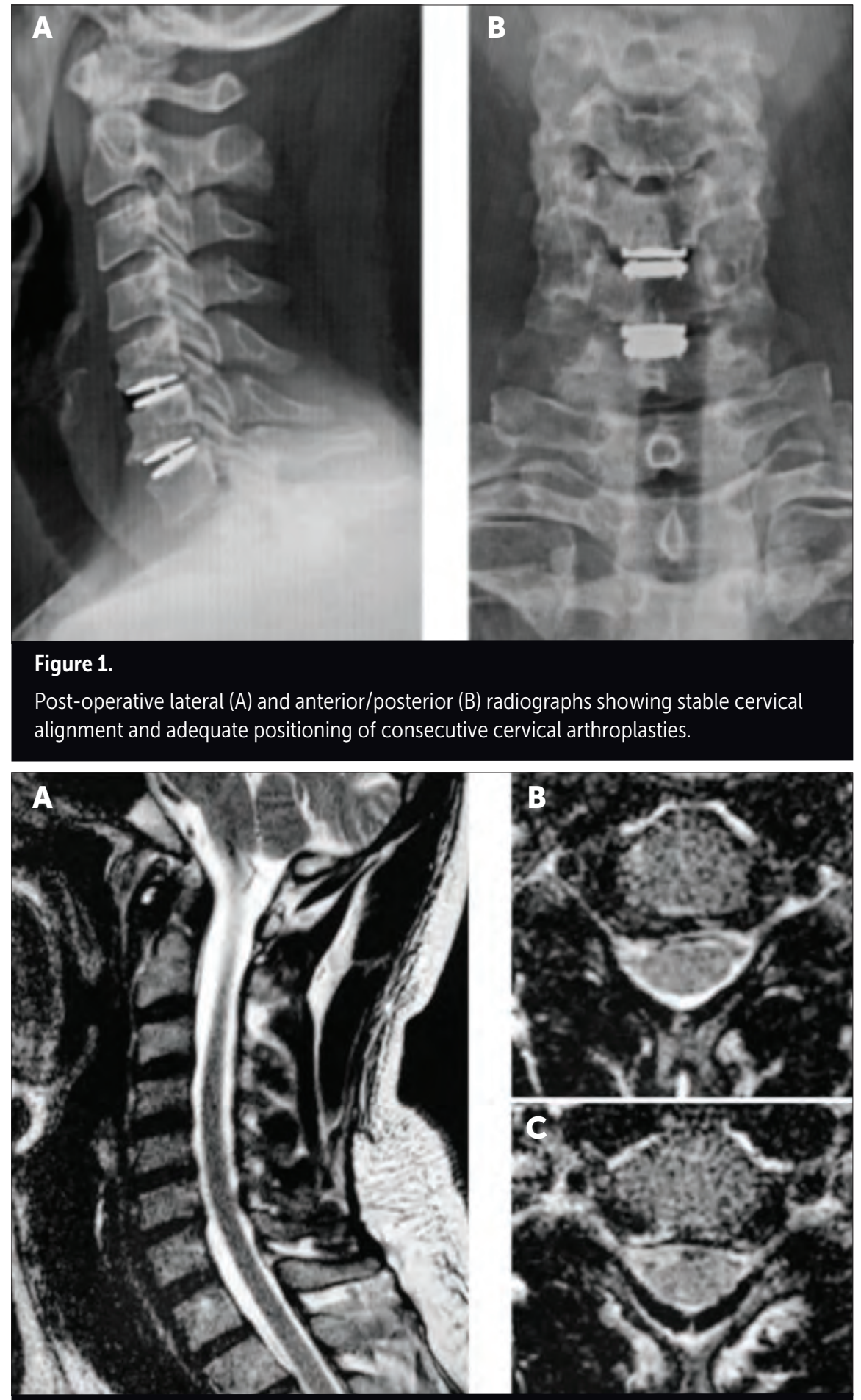

Figure 2.

Sagittal T2 MRI showing multi-level spondylotic changes without disc space collapse or kyphotic deformity (A). Axial MRI through the C5/6 (B) and C6/7 (C) disc spaces demonstrating broad based disc bulging that results in right foraminal stenosis at $\mathrm{C} 5 / 6$ and bilateral foraminal stenosis at C6/7. contraindications include active infection, malignancy, and metabolic or inflammatory spine diseases. Osteoporosis may increase the risk for implant migration. ${ }^{31}$

\section{CASE EXAMPLE}

A 45-year-old Caucasian male presented with eight months of neck pain with radiation down his right arm to his right thumb, index and middle finger. There was no inciting event or trauma. He was neurologically intact other than a right Spurling's sign. There was no clinical evidence of myelopathy.

On review of his cervical MRI, he had advanced spondylosis with right greater than left neural foraminal narrowing at C5-6. Spondylosis with bilateral foraminal narrowing was also noted at C6-7. (Figure 1)

He was treated with several weeks of physical therapy, cervical traction, and three epidural steroid injections without lasting improvement in his symptoms. Given his failure of conservative treatment, surgical decompression was recommended. The options of arthrodesis and arthroplasty were offered to the patient, who elected to undergo C5/6 and C6/7 arthroplasties.

Post-operatively, he recovered very well with complete resolution of his preoperative neck and arm symptoms. Radiographs confirmed adequate cervical alignment and device placement. (Figure 2) By 8 weeks post-op, he had returned to work without restrictions as an electrician.

\section{OUTCOMES}

Initial trials excluded multiple level arthroplasties or combined them with single level treatments in their analyses. In 2007, Pimenta reported that 2 or 3 level CDA experienced significantly greater improvements in patient outcomes Neck Disability Index (NDI) and Visual Analogue Score (VAS) - than single level arthroplasty at 3 years from surgery. ${ }^{32}$ Subsequent studies addressed multilevel disease independently.

One class-one randomized, controlled trial has been published comparing patients who underwent single and multiplelevel CDA. Clinical outcome scores were not significantly different between the two arms: both groups had similar NDI, VAS, Short Form 12 (SF-12 MCS/ 
PCS), and satisfaction scores. The rate of complications, subsequent surgeries, and heterotopic ossification were also not significantly different. ${ }^{27}$

In a systematic review, Joaquim identified two class-one randomized, controlled trials that compared contiguous multilevel arthroplasties against arthrodesis. ${ }^{33}$ In a 330 patient study, Davis found positive patient-reported outcomes with CDA: a significant decrease in NDI and SF-12 PCS that was maintained for 4 years of follow up and improved patient satisfaction scores. Neck pain and arm pain VAS scores were not significantly different, though neck pain scores were transiently lower with arthroplasty. ACDF had a higher rate of subsequent surgery on the index level, 4.0 vs $15.2 \%$, predominantly for symptomatic pseudoarthrosis. ${ }^{23}$

Radcliff conducted a second randomized, controlled trial in 325 patients. Similarly, NDI and SF-12 PCS were significantly lower with arthroplasty at all postoperative time points through 5 years of follow up. There was no difference in VAS scores for arm or neck pain. Again, a lower probability of subsequent surgery on index or adjacent levels was identified with arthroplasty. Range of motion was not significantly changed from pre-operative values by CDA. Rates of adjacent segment degeneration were assessed by the Kellgren-Lawrence scale: CDA had significantly less degeneration (50.7\%) than arthrodesis (90.5\%). These two studies suggest that ASD is not prevented by CDA, but patients with multilevel arthroplasty may develop radiographic changes and become symptomatic at a slower rate than those with multilevel ACDF for at least five years. ${ }^{24}$

\section{COMPLICATIONS}

Anterior cervical arthroplasty and arthrodesis share a similar complication profile due to their common surgical approach. Xu conducted a systematic review of arthroplasty trials and reported dysphagia/dysphonia at rates of 1.3 to $27.2 \%$, vascular injury including hematoma at 1.1 to $2.4 \%$, dural injury at 0.0 to $7.1 \%$, and wound infection at 1.2 to $22.5 \%$.

Dysphagia is a well-described approachrelated complication to anterior cervical surgery. In a cadaver model, placing three-level anterior cervical plate fixation was found to cause five-fold higher intraesophageal pressures than what is required to place equivalent level arthroplasties due to increased retraction. ${ }^{34} \mathrm{~A}$ prospective, randomized trial showed a decrease in dysphagia on the BazazYoo scale with zero-profile arthroplasty compared to arthrodesis with plate fixation. ${ }^{35}$ The etiology of the dysphagia may be attributable to the increased dissection and retraction required to introduce the plate or from the presence of a foreign body within the retropharyngeal space. Consecutive interbody fixation devices without an anterior plate may obviate this benefit of arthroplasty.

Heterotopic ossification $(\mathrm{HO})$ is a common complication of prosthetic joints, wherein new bony growth may inhibit movement of the prosthesis or cause compression of the neural elements. The McAfee classification divides $\mathrm{HO}$ of CDA into grades I/II, which comprise radiographic findings of bony growth and grades III/IV, which have clinical manifestations of limited movement. ${ }^{36}$ The pooled prevalence of $\mathrm{HO}$ in single and multilevel CDA across multiple studies has been reported as $58.2 \%$ at 2 years, with a $16.7 \%$ rate of grade III or above. ${ }^{37} \mathrm{Wu}$ reported higher rates of $\mathrm{HO}$ in two-level arthroplasty (75.0\%) compared to single level $(40.5 \%)$, with $14.3 \%$ of arthroplasties losing their mobility after multilevel surgery. ${ }^{38}$ In prospective trials of two-level arthroplasty, rates of clinically significant $\mathrm{HO}$ were $16.6 \%{ }^{23}$ and $29.7 \% .{ }^{24}$ Arthroplasties at C3/4 may also have higher levels of $\mathrm{HO}$ due to decreased physiologic motion at that level compared to the other subaxial segments. ${ }^{39}$

Implant migration is a rare complication of CDA that may produce iatrogenic injury. The largest report of symptomatic migrations comprised 5 patients who underwent single or multiple-level CDA in a single institution, with an overall rate of $0.4 \%$ of all cervical arthroplasties performed. ${ }^{40}$ In four cases, the device was explanted and revised with ACDF and in one patient, the implant was simply removed. Zhai reported a case of migration in a two-level arthroplasty that presented with dysphagia and was revised with a corpectomy of the middle vertebra and multilevel fusion. ${ }^{41}$ Of the large prospective trials on multiple level arthroplasties, only one case of migration was reported in a study of 255 patients with 4 years of follow-up. ${ }^{23}$

Sagittal fracture while preparing superior and inferior keels in a single vertebra is a unique complication of subsequent level arthroplasty. The few case reports available suggest that this is a rare phenomenon and may be managed with a rigid cervical collar, though prolonged post-operative pain may occur. ${ }^{42}$

\section{CONCLUSION}

Multilevel CDA has demonstrated unique biomechanics and complication profiles compared to arthrodesis and single-level arthroplasty. Multilevel arthroplasty offers advantages in patient-reported outcome measures to arthrodesis in appropriately selected patients.

\section{REFERENCES}

1. Lafuente J, Casey AT, Petzold A, Brew S. The Bryan cervical disc prosthesis as an alternative to arthrodesis in the treatment of cervical spondylosis: 46 consecutive cases. J Bone Joint Surg Br. 2005;87:508-12

2. Lin EL, Wang JC. Total disk arthroplasty. J Am Acad Orthop Surg. 2006;14:705-14.

3. Shim CS, Lee SH, Park HJ, Kang HS, Hwang $\mathrm{JH}$. Early clinical and radiologic outcomes of cervical arthroplasty with Bryan Cervical Disc prosthesis. J Spinal Disord Tech. 2006;19:465-70

4. Yoon DH, Yi S, Shin HC, Kim KN, Kim SH Clinical and radiological results following cervical arthroplasty. Acta Neurochir (Wien). 2006;148:943-50.

5. Heller JG, Sasso RC, Papadopoulos SM, Anderson PA, Fessler RG, Hacker RJ, et al. Comparison of BRYAN cervical disc arthroplasty with anterior cervical decompression and fusion: clinical and radiographic results of a randomized, controlled, clinical trial. Spine (Phila Pa 1976). 2009;34:101-7.

6. Mummaneni PV, Burkus JK, Haid RW, Traynelis VC, Zdeblick TA. Clinical and radiographic analysis of cervical disc arthroplasty compared with allograft fusion: a randomized controlled clinical trial. J Neurosurg Spine. 2007:6:198-209.

7. Murrey D, Janssen M, Delamarter R, Goldstein J, Zigler J, Tay B, et al. Results of the prospective, randomized, controlled multicenter Food and Drug Administration investigational device exemption study of the ProDisc-C total disc replacement versus anterior discectomy and fusion for the treatment of 1-level symptomatic cervical disc disease. Spine J. 2009;9:275-86. 
8. Sasso RC, Anderson PA, Riew KD, Heller JG. Results of cervical arthroplasty compared with anterior discectomy and fusion: fouryear clinical outcomes in a prospective, randomized controlled trial. Orthopedics 2011;34:889

9. Upadhyaya CD, Wu JC, Trost G, Haid RW, Traynelis VC, Tay B, et al. Analysis of the three United States Food and Drug Administration investigational device exemption cervical arthroplasty trials. J Neurosurg Spine. 2012;16:216-28.

10. Park JH, Roh KH, Cho JY, Ra YS, Rhim SC, Noh SW. Comparative analysis of cervical arthroplasty using mobi-c(r) and anterior cervical discectomy and fusion using the solis(r) -cage. J Korean Neurosurg Soc. 2008;44:217-21.

11. Luo J, Wang H, Peng J, Deng Z, Zhang Z, Liu S, et al. Rate of Adjacent Segment Degeneration of Cervical Disc Arthroplasty Versus Fusion Meta-Analysis of Randomized Controlled Trials. World neurosurgery. 2018;113:225-31.

12. Ning GZ, Kan SL, Zhu RS, Feng SQ. Comparison of Mobi-C Cervical Disc Arthroplasty Versus Fusion for the Treatment of Symptomatic Cervical Degenerative Disc Disease. World neurosurgery. 2018;114:e224e39.

13. Nunley PD, Coric D, Frank KA, Stone MB. Cervical Disc Arthroplasty: Current Evidence and Real-World Application. Neurosurgery. 2018;83:1087-106.

14. Janssen ME, Zigler JE, Spivak JM, Delamarter RB, Darden BV, 2nd, Kopjar B. ProDisc-C Total Disc Replacement Versus Anterior Cervical Discectomy and Fusion for Single-Level Symptomatic Cervical Disc Disease: Seven-Year Follow-up of the Prospective Randomized U.S. Food and Drug Administration Investigational Device Exemption Study. J Bone Joint Surg Am. 2015;97:1738-47.

15. Hilibrand AS, Robbins M. Adjacent segment degeneration and adjacent segment disease: the consequences of spinal fusion? Spine J. 2004;4:190S-4S.

16. Elsawaf A, Mastronardi L, Roperto R, Bozzao A, Caroli M, Ferrante L. Effect of cervical dynamics on adjacent segment degeneration after anterior cervical fusion with cages. Neurosurg Rev. 2009;32:215-24; discussion 24.

17. Cho SK, Riew KD. Adjacent segment disease following cervical spine surgery. J Am Acad Orthop Surg. 2013;21:3-11.

18. Li Y, Shen H, Khan KZ, Fang S, Liao Z, Liu W. Comparison of Multilevel Cervical Disc Replacement and Multilevel Anterior Discectomy and Fusion: A Systematic Review of Biomechanical and Clinical Evidence. World neurosurgery. 2018;116:94-104.

19. Barrey C, Campana S, Persohn S, Perrin G, Skalli W. Cervical disc prosthesis versus arthrodesis using one-level, hybrid and twolevel constructs: an in vitro investigation. Eur Spine J. 2012;21:432-42.
20. Faizan A, Goel VK, Biyani A, Garfin SR, Bono CM. Adjacent level effects of bi level disc replacement, bi level fusion and disc replacement plus fusion in cervical spine--a finite element based study. Clin Biomech (Bristol, Avon). 2012;27:226-33.

21. Chung TT, Hueng DY, Lin SC. Hybrid Strategy of Two-Level Cervical Artificial Disc and Intervertebral Cage: Biomechanical Effects on Tissues and Implants. Medicine (Baltimore). 2015;94:e2048

22. Park J, Shin JJ, Lim J. Biomechanical analysis of disc pressure and facet contact force after simulated two-level cervical surgeries (fusion and arthroplasty) and hybrid surgery. World neurosurgery. 2014;82:1388-93.

23. Davis RJ, Nunley PD, Kim KD, Hisey MS, Jackson RJ, Bae HW, et al. Two-level total disc replacement with Mobi- $\mathrm{C}$ cervical artificial disc versus anterior discectomy and fusion: a prospective, randomized, controlled multicenter clinical trial with 4-year follow-up results. J Neurosurg Spine. 2015;22:15-25.

24. Radcliff K, Coric D, Albert T. Five-year clinical results of cervical total disc replacement compared with anterior discectomy and fusion for treatment of 2-level symptomatic degenerative disc disease: a prospective, randomized, controlled, multicenter investigational device exemption clinical trial. $\mathrm{J}$ Neurosurg Spine. 2016;25:213-24

25. Kong L, Cao J, Wang L, Shen Y. Prevalence of adjacent segment disease following cervical spine surgery: A PRISMA-compliant systematic review and meta-analysis. Medicine (Baltimore). 2016;95:e4171.

26. Lopez-Espina CG, Amirouche F, Havalad V. Multilevel cervical fusion and its effect on disc degeneration and osteophyte formation. Spine (Phila Pa 1976). 2006;31:972-8.

27. Bae HW, Kim KD, Nunley PD, Jackson RJ, Hisey MS, Davis RJ, et al. Comparison of Clinical Outcomes of 1- and 2-Level Total Disc Replacement: Four-Year Results From a Prospective, Randomized, Controlled, Multicenter IDE Clinical Trial. Spine (Phila Pa 1976). 2015;40:759-66.

28. Chang HK, Huang WC, Wu JC, Tu TH, Fay LY, Chang PY, et al. Cervical Arthroplasty for Traumatic Disc Herniation: An Age- and Sex-matched Comparison with Anterior Cervical Discectomy and Fusion. BMC Musculoskelet Disord. 2015;16:228.

29. Keachie K, Shahlaie K, Muizelaar JP. Upper thoracic spine arthroplasty via the anterior approach. J Neurosurg Spine. 2010;13:240-5.

30. Ding D, Shaffrey ME. Cervical disk arthroplasty: patient selection. Clin Neurosurg. 2012;59:91-7.

31. Leven D, Meaike J, Radcliff K, Qureshi S Cervical disc replacement surgery: indications, technique, and technical pearls. Curr Rev Musculoskelet Med. 2017;10:160-9.
32. Pimenta L, McAfee PC, Cappuccino A, Cunningham BW, Diaz R, Coutinho E. Superiority of multilevel cervical arthroplasty outcomes versus single-level outcomes: 229 consecutive PCM prostheses. Spine (Phila Pa 1976). 2007;32:1337-44.

33. Joaquim AF, Riew KD. Multilevel cervical arthroplasty: current evidence. A systematic review. Neurosurg Focus. 2017;42:E4.

34. Tortolani PJ, Cunningham BW, Vigna F, Hu $\mathrm{N}$, Zorn CM, McAfee PC. A comparison of retraction pressure during anterior cervical plate surgery and cervical disc replacement: a cadaveric study. J Spinal Disord Tech. 2006;19:312-7.

35. Segebarth B, Datta JC, Darden B, Janssen ME, Murrey DB, Rhyne A, et al. Incidence of dysphagia comparing cervical arthroplasty and ACDF. SAS J. 2010;4:3-8.

36. McAfee PC, Cunningham BW, Devine J, Williams E, Yu-Yahiro J. Classification of heterotopic ossification $(\mathrm{HO})$ in artificial disk replacement. J Spinal Disord Tech. 2003:16:384-9.

37. Chen J, Wang X, Bai W, Shen X, Yuan W. Prevalence of heterotopic ossification after cervical total disc arthroplasty: a meta-analysis. Eur Spine J. 2012;21:674-80.

38. Wu JC, Huang WC, Tsai HW, Ko CC, Fay LY, Tu $\mathrm{TH}$, et al. Differences between 1- and 2-level cervical arthroplasty: more heterotopic ossification in 2-level disc replacement: Clinical article. J Neurosurg Spine. 2012;16:594-600.

39. Chang PY, Chang HK, Wu JC, Huang WC, Fay LY, Tu TH, et al. Differences between C3-4 and other subaxial levels of cervical disc arthroplasty: more heterotopic ossification at the 5-year follow-up. J Neurosurg Spine. 2016;24:752-9.

40. Ozbek Z, Ozkara E, Arslantas A. Implant Migration in Cervical Disk Arthroplasty. World neurosurgery. 2017;97:390-7.

41. Zhai JL, Chang X, Hu JH, Weng XS. A Case of Implant Migration Following Bi-level Cervical Disc Arthroplasty. Chin Med J (Engl). 2017;130:497-8.

42. Datta JC, Janssen ME, Beckham R, Ponce C. Sagittal split fractures in multilevel cervical arthroplasty using a keeled prosthesis. J Spinal Disord Tech. 2007;20:89-92. 